\title{
SELECTED APPLICATIONS OF STIMULI-RESPONSIVE POLYMERS: 4D PRINTING BY THE FUSED FILAMENT FABRICATION TECHNOLOGY
}

\author{
Y. Ahroni1, N. Dresler1, A. Ulanov1, D. Ashkenazi2, M. Aviv1, \\ M. Librus ${ }^{3}, A$. Stern ${ }^{1,4}$ \\ ${ }^{1}$ School of Mechanical Engineering, Afeka Academic College of Engineering, Tel Aviv 6910717, Israel \\ ${ }^{2}$ School of Mechanical Engineering, Tel Aviv University, Ramat Aviv 6997801, Israel \\ ${ }^{3}$ Synergy R.M ltd, P.O.Box 8631, Netanya 4250416, Israel \\ ${ }^{4}$ Department of Materials Engineering, Ben Gurion University of the Negev, Beer Sheva 8410501, Israel \\ *Corresponding author's e-mail address: dana@eng.tau.ac.il
}

\begin{abstract}
In the past few years four-dimensional (4D) printing technologies have attained worldwide interest and they are now considered the "next big thing". The aim of this research is to provide three selected examples of stimuli-responsive polymer (SRP) applications additively manufactured (AM) by the fused filament fabrication (FFF) technique. To that end, a CCT BLUE filament of thermo-responsive polymer was chosen to produce a water temperature indicator, which changes colour from blue to white when temperature increases; a CCU RED filament of photo-responsive polymer was used to produce a sunlight / UV indicator bracelet; a transparent PLA CLEAR polymer, a CCU RED photo-responsive polymer, and an electrical conductive PLA polymer were selected to produce a smart business card stand. The temperature indicator capability was analysed based on examining colour changes as a function of temperature changes. The sunlight/UV indicator capability was analysed based on the inspection of colour change as a function of absorbed sun/ultraviolet light. The electrical conductivity of the conductive PLA polymer was examined by performing resistance measurements. All three objects were successfully produced and their functionality was demonstrated. We hope that these examples will catalyse the expansion of FFF $4 D$ printed SRP applications, as much work remains to be done in designing the parts and developing FFF printing parameters that take advantage of the stimuli-responsive materials currently being developed for FFF technology.
\end{abstract}

KEYWORDS: Additive manufacturing, 4D printing, Fused Filament Fabrication, Stimuli-responsive polymers.

\section{INTRODUCTION}

\subsection{D Printing}

Current developments in additive manufacturing (AM) technologies make it possible to build complex shapes that were previously impossible by traditional manufacturing techniques. In a 2013 Technology, Entertainment, Design (TED) talk, Mr. Skylar Tibbits of the Massachusetts Institute of Technology (MIT), first proposed the term "4D printing" presenting a rope-like printed item, which was able to form the "MIT" monogram when immersed in water [1]. Four-dimensional (4D) printing allows an AM printed structure to modify its configuration and/or property with time in reaction to external stimuli such as heat, light, electric voltage and current, magnetism, pressure, sound, motion, environmental stimuli, $\mathrm{pH}$, and more [1]-[11] (Fig. 1). The fundamental assumption of 4D printing is the ability to combine the design of shape and/or property change with a proper AM material and with an AM process, which should ultimately simplify the product's design strategy and the manufacturing process [4], [11]-[14].

\subsection{Fused Filament Fabrication}

Fused filament fabrication (FFF) has been revolutionizing the methods whereby components are prototyped and manufactured; the technique is the most widely used AM technology employing a melted filament of thermoplastic polymer to construct the 
3D-printed components by depositing extruded melted material line-by-line and then consecutively layer-by-layer. The reversible temperature phase transformation of thermoplastic materials enables the polymers to be employed in the FFF extrusion-based methods. Almost all FFF printers today rely upon thermoplastic materials as fibers/filaments. Among the common thermoplastic polymers are poly(lactic acid) (PLA), poly(caprolactone) (PCL), and acrylonitrile butadiene styrene (ABS) copolymer that make use of extrusion temperatures within the range of $100-250^{\circ} \mathrm{C}$. ABS is a terpolymer with a higher glass transition temperature $\left(\mathrm{Tg} \sim 105^{\circ} \mathrm{C}\right)$ than both PCL and PLA; it tends to be less brittle than the PLA and PCL polymers. The FFF print platform should also be heated to avoid fast contraction and warping of the printed items. The cooling speed of the filaments directly affects the interlayer/intralayer adhesion and the mechanical properties of the printed objects [15].

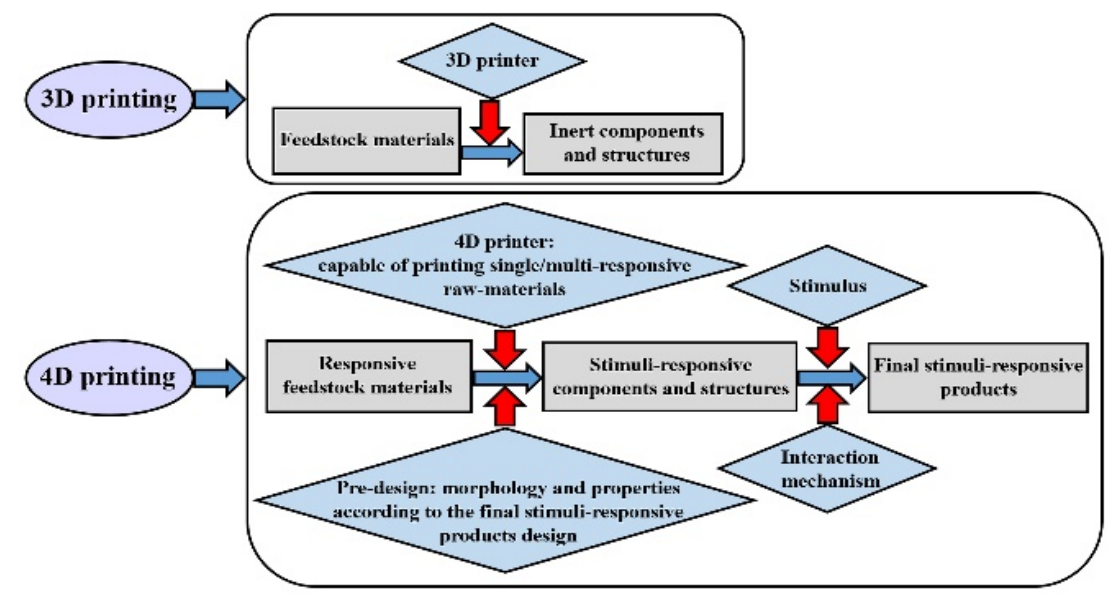

Fig. 1. Schematic representation of 3D vs. 4D printing; 4D printed structures can modify their configurations or/and properties with time in response to external stimuli

The expected resolution of the FFF technique is basically limited by the diameter of the extruder's nozzle; nozzle diameters typically range from 100 to $400 \mu \mathrm{m}$ or even bigger. Quality and printing time determine diameter choice. For a given nozzle diameter, the combination of extruder velocity and nozzle speed on the $\mathrm{X}, \mathrm{Y}$ directions should be optimized. The FFF method presents significant advantages over the classical production technologies employed [10]-[12]. This technique permits the production of completely customized products economically for limited quantities. Some reports estimate that FFF is competitive with plastic injection molding for targeted products below 1000 items [9][12]. The low fabrication cost is linked to the fact that molds and costly tools, machining, and other complex/expensive finishing processes are not required.

\subsection{Stimuli-Responsive Polymers and Selected Applications}

The development of FFF technology has been made possible due to a broad variety of thermoplastic filaments with various properties, including stimuliresponsive materials, which are currently available commercially and/or under development. Selected stimuli-responsive polymers (SRP), occasionally referred to as "smart" polymers, have been synthesized to respond to a variety of external stimuli. They are able to alter their properties when exposed to a specific stimulus, that may include temperature (thermo-responsive materials), light (photoresponsive materials), electricity (electro-responsive materials), stress/pressure (mechano-responsive materials), among others [16]. Thermochromic materials respond to the change in temperature by modifying their colour. A common example is the use of thermochromic paints that create a coating on a ceramic cup, which changes colour when a hot drink is poured inside. The transformation is reversible since the colour of the mug switches back to the original one when it cools to room temperature. Thermochromism is a widespread phenomenon in various chemical systems, both inorganic and organic. Inorganic materials, especially oxides, exhibit thermochromism by undergoing phase transition or charge-transfer bands near the visible region dependent on temperature [17]. On the other hand, organic materials, such as various polymers and small molecules, exhibit thermochromism, which can be activated by two common processes: temperaturedependent structural rearrangements or thermally driven reversible reactions. In the first case, the crystalline structural changes in liquid or photonic crystal reversely change its scattering properties and makes the material reflective or opaque. In the second case, reversible charge transfer, bond rearrangements, 
or stereoisomerism changes the material's absorption spectrum and causes a colour change [17]. The latter approach usually consists of at least three components, namely, a colour former, a colour developer and a solvent. Common colour formers are the electron-donating, Leuco dyes. Their reaction to the second component, the electron-accepting developer, defines the position of the longest wavelength absorption which causes coloration/discoloration. The melting point of the third component, the solvent, controls the temperature at which the colour of the thermochromic complex changes [18]. Reversible discoloration occurs through two competing reactions: one between the dye and the developer, and the other between the solvent and the developer. The first reaction occurs at lower temperatures, where the solvent exists in its solid form. This reaction yields coloured complexes. At a higher temperature, when the solvent melts, it binds to the developer and thus breaks down the dye-developer bond. In this mode the system is colourless [19].

Thermochromic systems based on Leuco dyes are used as carriers of heat induced colour changes in various applications, such as in the fields of engineering drawings, biochemical analysis, lightemitting probes, invoices, and printing inks [20], showing good sensitivity and thermochromic stability. Thermochromic printing inks are mostly based on functional polymers which encapsulate the thermochromic complex dye-developer-solvent, providing a thermochromic property to the polymer. Generally, the organic Leuco dyes are available in a wide variety of colours, for temperatures between $-6^{\circ} \mathrm{C}$ and $60^{\circ} \mathrm{C}$; the colour changes happen at an approximate $3^{\circ} \mathrm{C}$ gap. Microencapsulation allows their use in a variety of materials and products. The size of the microcapsules typically ranges between 3 and $5 \mu \mathrm{m}$ (over 10 times larger than regular pigment particles), which requires some adjustments to the manufacturing processes [16], [21]-[23].

Photo-responsive (photochromic) materials change their physicochemical properties as a response to light irradiation of appropriate wavelengths and intensity. These materials are usually employed in context with the limitation of ultraviolet (UV) and infrared (IR) radiations, such as in the case of windows for adaptive solar control or optical lenses for solar light protection [24]. The light-control of photo-responsive polymers has many inherent advantages compared to other external stimuli. These include a simple noncontact command, easy adjustment to the intensity of the response, and creating the precise positional and temporal reaction. The application potential of the photo-responsive polymers is determined by three main considerations: (i) the extent of the property change, (ii) the materialization rate of this change, and (iii) the reversibility of the change. The most extensively studied photo-responsive polymers in the literature comprise light responsive moieties, namely, chromophores, based on azobenzenes, spiropyrans and spirooxazines, and groups undergoing cycloaddition upon light irradiation, such as cinnamic esters, coumarin and diarylethenes [25]. Light sources as UV laser, lamp or sunlight, initiate chemical reactions which change the chromophore structure and modify their chemical and mechanical properties. Some of the most common processes involved in photochromism are pericyclic reactions, cis-trans isomerizations, intramolecular hydrogen transfer, intramolecular group transfers, dissociation processes and electron transfers (oxidation-reduction). The chromophore has two states of the molecule which are thermally stable under ambient conditions for a reasonable time, and their interconversion can be controlled using different wavelengths of light. The visible colour of a photo-responsive material is frequently dictated by the wavelength of light "reflected" by the material's lattice spacing [26]-[27].

Photoresponsive polymers incorporating azobenzenes are especially well regarded and have received the most attention because of their versatile design and synthesis [26]. These polymers exhibit light-induced, reversible isomerization of the azobond between the thermally stable "trans" state (discoloured state) and the metastable "cis" configuration (coloured state). Generally, the azobenzenes can be isomerized from "trans" to "cis" using a UV wavelength of 300-400 nm. The "cis" created isomers will convert back under visible illumination at above $400 \mathrm{~nm}$ to the stable "trans" state [28]. An alternating method composed of lanthanide-aspartic acid nanoscale coordination polymers blended with PLA has recently been used to generate fluorescent quick-read codes within FFF printed objects, acting as an original anticounterfeiting procedure; the composite PLA parts exhibit reddish-pink or blue-green fluorescence when exposed to UV light [29].

Limited types of electro-responsive (conductive) polymers have been used for the 4D printing of objects; recently some conductive polymers have been developed for FFF printing and used for electrical circuits and sensors [30-32]. In this context, the resistivity and temperature dependence of resistivity for FFF filaments compared to FFF printed samples were studied for PLA-carbon black and PLAgraphene composites. The electrical resistivity findings can be used to support the design and modelling of FFF electronics and sensors, and in making the choice between commercially available conductive PLA filaments [26]. Because ABS is thermally and chemically resistant, mechanically tough, and low-cost, it is often commonly used in the electronics industry. Thus, ABS composites with various metal-oxides have been used to produce patterned, 3D printed dielectric materials; other applications include the use of ABS filled with steel micro-powder used to manufacture electro-magnetic sensors. 
Stimuli-responsive polymers have the potential for various applications, including smart devices, soft materials that expand or contract, biomedical applications and pharmaceutical care, wearable electronics, soft robotics, aerospace, and renewable energy [13]-[16], [21]-[33]. The current research deals with the $4 \mathrm{D}$ printing of three objects by the FFF technique, made from different selected stimuliresponsive polymers. The water temperature indicator consisted of a thermo-responsive polymer (CCT BLUE), the sunlight / UV indicator bracelet was made of a photo-responsive polymer (CCU RED), and the professional smart business card-stand for the office tabletop was made of three different polymers: transparent polymer (PLA clear), electrical conductive polymer (conductive PLA), and photo-responsive polymer (CCU RED).

\section{EXPERIMENTAL METHODS}

Three applications were designed and produced with AM-FFF printers, including water temperature indicator for the shower tap, sunlight / UV indicator bracelet, and smart business card-stand for office tabletop, as described below (Table 1). The printing parameters were varied from one application to another based on mechanical design and manufacturing considerations. Each material has its own printing parameters in accordance with the manufacturer's instructions (nozzle temperature and tray temperature). Print speed depends on design.

The more complicated the geometry, the slower the printing speed. The density was determined from the design and regulated according to functionality considerations.

Table 1. The designed 4D printing applications and their 3D printing parameters

\begin{tabular}{|c|c|c|c|c|c|}
\hline Part name & $\begin{array}{c}\text { Water temperature } \\
\text { indicator }\end{array}$ & $\begin{array}{l}\text { UV indicator } \\
\text { bracelet }\end{array}$ & \multicolumn{3}{|c|}{ Business card-stand } \\
\hline Material & $\begin{array}{c}\text { CCT BLUE } \\
(\mathrm{eSUN})\end{array}$ & $\begin{array}{l}\text { CCU RED } \\
(\text { eSUN) }\end{array}$ & $\begin{array}{l}\text { PLA CLEAR } \\
\text { (eSUN) }\end{array}$ & $\begin{array}{l}\text { Conductive } \\
\text { PLA (Proto) }\end{array}$ & $\begin{array}{l}\text { CCU RED } \\
\text { (eSUN) }\end{array}$ \\
\hline & Creality & Creality & Creality & Creality3D & Creality3D \\
\hline FDM 3D printer & Ender 3 & Ender 3 & Ender 3 & CR10s Pro & Ender 3 \\
\hline Filament diameter [mm] & 1.75 & 1.75 & 1.75 & 1.75 & 1.75 \\
\hline Nozzle temperature $\left[{ }^{\circ} \mathrm{C}\right]$ & 210 & 210 & 200 & 225 & 210 \\
\hline Nozzle diameter [mm] & 0.4 & 0.4 & 0.4 & 0.4 & 0.4 \\
\hline Build plate temperature $\left[{ }^{\circ} \mathrm{C}\right]$ & 60 & 60 & 60 & 50 & 60 \\
\hline Layer height [mm] & 0.2 & 0.2 & 0.2 & 0.3 & 0.2 \\
\hline Infill [\%] & $90 \%$ & $90 \%$ & $20 \%$ & $80 \%$ & $100 \%$ \\
\hline
\end{tabular}

\subsection{Application A: Water Temperature Indicator}

The 4D-printed water temperature indicator was printed by means of Creality $3 \mathrm{D} \otimes$ Ender-3 3D printer (Fig. 2 and 3), with a fully open source. For that purpose, a thermo-responsive polymer was selected, which changes colour from blue to white when the temperature is increased, with a response time for the initial colour change of 1-2 seconds, and a response time of 5 to 6 seconds until the colour changes to dark blue. The device, with a total length of $33 \mathrm{~mm}$ and external cross-section of $21 \mathrm{~mm} \times 30 \mathrm{~mm}$ (Fig. 2a-b), was designed with computer aided design (CAD) software, using the SolidWorks 2019 program.

The chosen polymer was CCT BLUE filament, produced by eSUN (China). The thermo-responsive polymer filament, with a $1.75 \mathrm{~mm}$ diameter (with nozzle diameter of $0.4 \mathrm{~mm}$ ), was extruded at a temperature of $210^{\circ} \mathrm{C}$, the building plate was preheated to $60^{\circ} \mathrm{C}$, the nozzle speed through extrusion was up to $50 \mathrm{~mm} / \mathrm{sec}$, and the layer thickness was of $0.2 \mathrm{~mm}$.

The device was printed in the high-density filling mode of $90 \%$ of the volume (Table 1). The temperature of the 3D-printed indicator was measured with a fast response ANENG AN8009 thermocouple
(China), with an approximation error of $\pm 1^{\circ} \mathrm{C}$, attached to surface of the object inside the water medium. The temperature indicator was photographed immediately upon its removal from the water.

\subsection{Application B: Sunlight / UV Indicator Bracelet}

The sunlight / UV indicator bracelet was produced by AM-FFF (Fig. 4 and 5). For that purpose, a photoresponsive polymer was chosen, which changes colour from white to red when exposed to intense sunlight / UV radiation, with a response time of 1-2 seconds. The device was designed with CAD software, using the SolidWorks 2019 program.

The chosen polymer was CCU RED filament, produced by eSUN (China), which was printed by means of the Creality $3 \mathrm{D} \otimes$ Ender-3 3D printer (Fig. 5). This filament changes colour when it absorbs sun/ultraviolet (UV) energy. When the radiation of sun/UV is reduced, the filament turns back again to its original colour. The photo-responsive polymer filament, with a $1.75 \mathrm{~mm}$ diameter and nozzle diameter of $0.4 \mathrm{~mm}$ was extruded at $210^{\circ} \mathrm{C}$. The building plate temperature was $60^{\circ} \mathrm{C}$, the velocity of the nozzle during extrusion was up to $50 \mathrm{~mm} / \mathrm{sec}$, and each layer thickness was $0.2 \mathrm{~mm}$. The bracelet was 
printed with filling mode density of $90 \%$ of the volume (Table 1). The colour change measurements were performed with a Lux Light Meter app, by using the illuminance sensor installed in the phone, resulting in illumination intensity values given in Lux units (symbol: 1x), with an approximation error of \pm 1

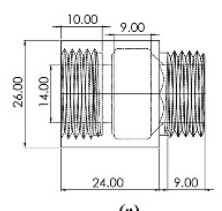

(a)

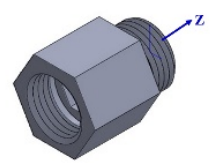

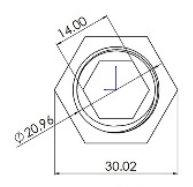

(b)

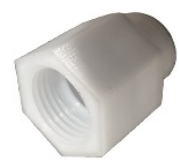

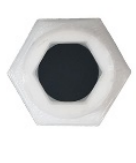

(c)

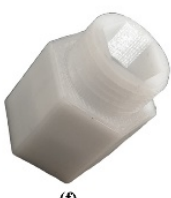

(f)
Fig. 2. The 4D-printed AM-FFF water temperature indicator device: a)-b) CAD model of the front and top view (designed with SolidWorks 2019); c) top view of the printed part; d) isometric view (CAD model); e)-f) isometric view of the printed part

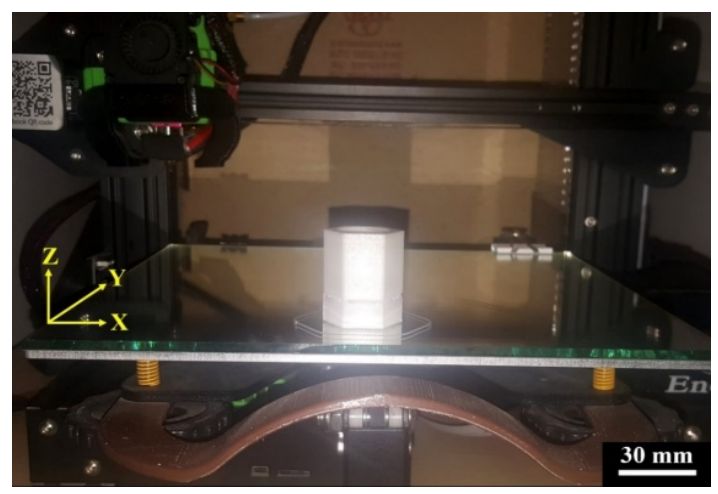

Fig. 3. The 4D-printed AM-FFF water temperature indicator inside the 3D-priting machine: the part before the removal of the support material

\subsection{Application C: Professional Smart Business cad Stand for Office Tabletop}

The office tabletop professional business card stand was printed using three different polymers: (1) transparent polymer, (2) electrical conductive polymer, and (3) photo-responsive polymer (Fig. 6a). The device, whose dimensions are of about $114 \mathrm{~mm} \times 73$ $\mathrm{mm} \times 65 \mathrm{~mm}$ (Fig. 6b), was designed with the SolidWorks 2019 CAD program. The chosen semitransparent polymer was PLA clear filament, produced by eSUN, printed by Creality $3 \mathrm{D} \otimes$ Ender-3 $3 \mathrm{D}$ printer (white box, Fig. 7a). This polymer filament diameter
Lux. The measurements were performed between 12:00 and 13:00 with an exposure time of 10 seconds per measurement, and at each stage the samples were photographed in the same direction to which the camera sensor was pointed.
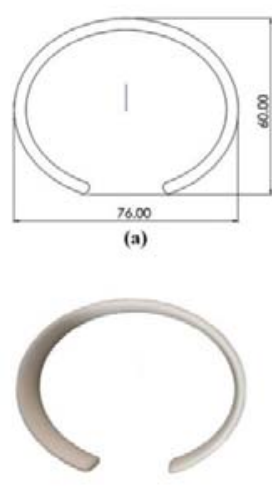

(d)

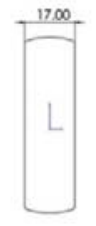

(b)

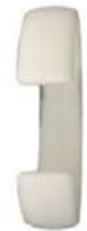

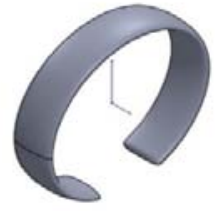

(c)

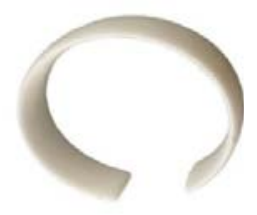

(f)
Fig. 4. The sunlight / UV indicator bracelet: a)-b) CAD model of the front and side view, respectively (designed with SolidWorks 2019); c) isometric view (CAD model); d)-f) front, side and isometric view of the printed bracelet, respectively, made of photoresponsive polymer

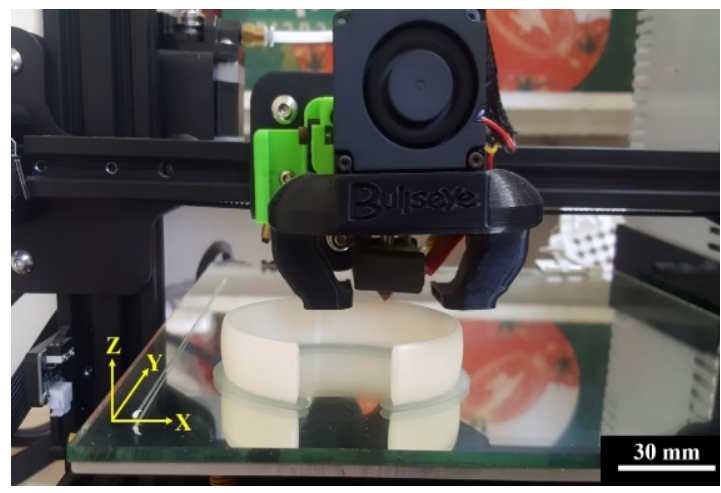

Fig. 5. The 4D-printed AM-FFF sunlight / UV indicator bracelet inside the 3D-printing machine

was $1.75 \mathrm{~mm}$; and it was extruded at a temperature of $200^{\circ} \mathrm{C}$, a building plate temperature of $60^{\circ} \mathrm{C}$, and the nozzle speed of up to $50 \mathrm{~mm} / \mathrm{sec}$. Each single layer thickness was $0.2 \mathrm{~mm}$, with a filling mode density of $20 \%$ of the volume. The selected electrically conductive polymer was conductive PLA produced by Proto, and printed by a Creality 3D CR10s Pro printer (Fig. 7b). This polymer filament diameter was 1.75 $\mathrm{mm}$, and it was extruded at a temperature of $225^{\circ} \mathrm{C}$ (with nozzle speed of up to $50 \mathrm{~mm} / \mathrm{sec}$ ) and with a building plate temperature of $50^{\circ} \mathrm{C}$. The single layer thickness of the conductive PLA was $0.3 \mathrm{~mm}$, with a filling mode density of $80 \%$ of the volume. 


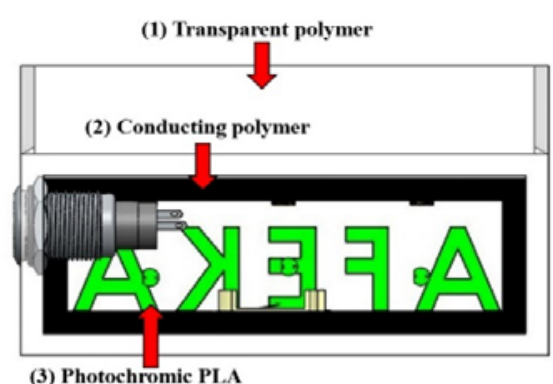

(a)

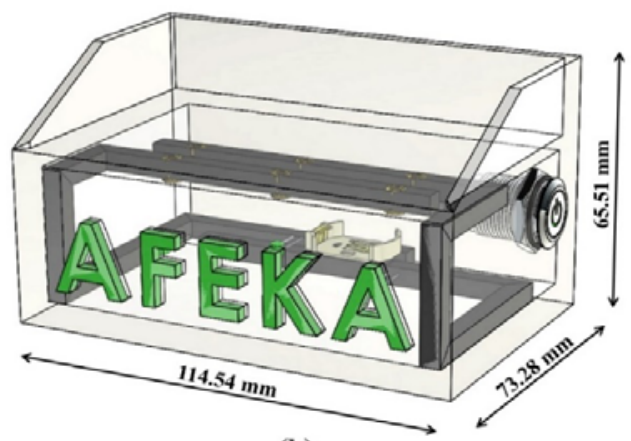

(b)

Fig. 6. The 4D-printed card holder CAD model: a) front view; b) isometric view
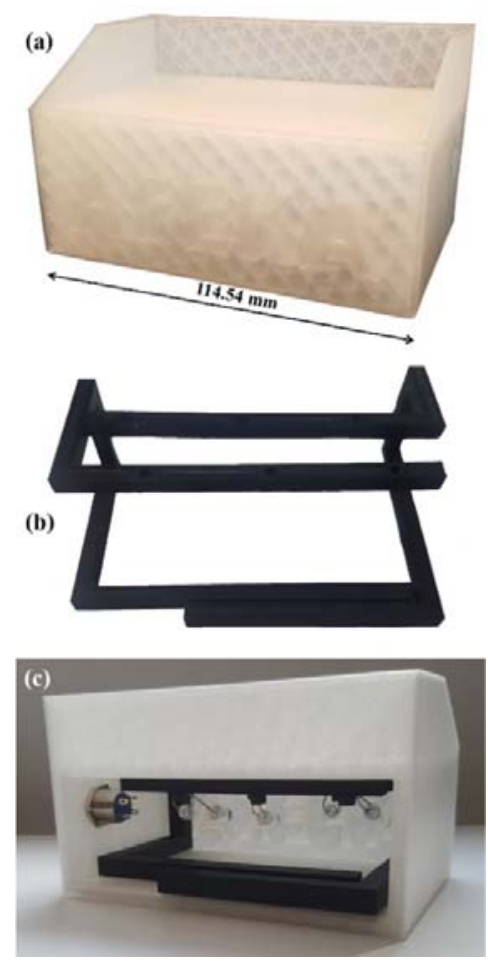

Fig. 7. The 4D-printed AM-FFF card holder: a) isometric view of the printed semi-transparent polymer (white box) and the photo-responsive polymer (letters); b) isometric view of the electrical conductor printed part of the card holder; c) the general part including the LED light source
The chosen sunlight/UV photo-responsive polymer (Fig. 6 and 7a) was made of CCU RED (eSUN, China) filament, which was 3D-printed by a Creality $3 \mathrm{D} \AA$ Ender-3 printer. This polymer was extruded at a temperature of $210^{\circ} \mathrm{C}$, with a building plate temperature of $60{ }^{\circ} \mathrm{C}$, and a layer thickness of $0.2 \mathrm{~mm}$. The letters were printed with a solid filling mode density of $100 \%$ of the volume (Table 1). Following the $3 \mathrm{D}$ printing process, the parts of the business card stand were assembled, including the UV light-emitting diode (LED) source (Fig. 6c).

Ten bars, with a square cross-section of $7 \mathrm{~mm} \times 7$ $\mathrm{mm}$ and length of $100 \mathrm{~mm}$, were 3D printed out of electrical conductive PLA polymer in order to measure electrical resistance (Fig. 8). Five bars were printed in the $\mathrm{Z}$ direction (perpendicular to the print tray) and another five bars in the $Y$ direction (parallel to the print tray). The average mass of the $\mathrm{Z}$ direction specimens was $6.1 \mathrm{~g}$, and that of the $\mathrm{Y}$ direction specimens was $5.6 \mathrm{~g}$.

The electrical resistance measurements of the bars were performed between two points by using an Escort 97 (Escort Company, Hong Kong) digital multimeter, with the resistance range of $400 \Omega$ to 40 $\mathrm{M} \Omega$. The Escort 97 instrument has a resistance resolution of $0.1 \Omega$ to $10 \mathrm{k} \Omega$ and an accuracy of 400 $\Omega-4 \mathrm{M} \Omega \pm 0.2 \% \mathrm{rdg}+3$ digits and $40 \mathrm{M} \Omega \pm 1 \% \mathrm{rdg}+$ 5 digits. The AC voltage range for the Escort 97 instrument is between $40 \mathrm{mV}$ and $750 \mathrm{~V}$.

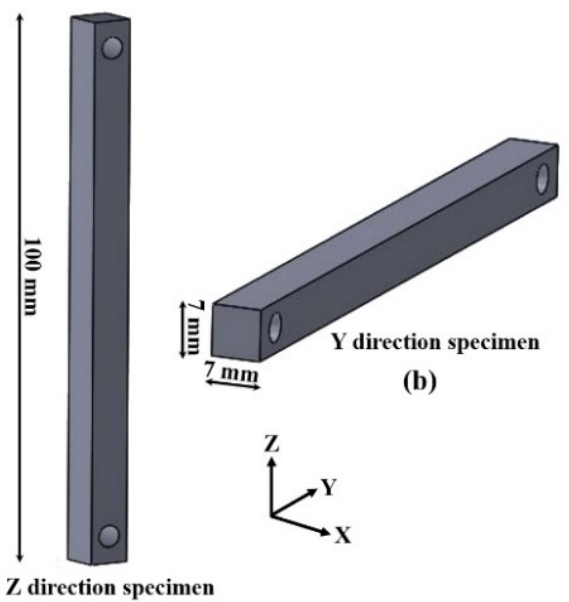

(a)

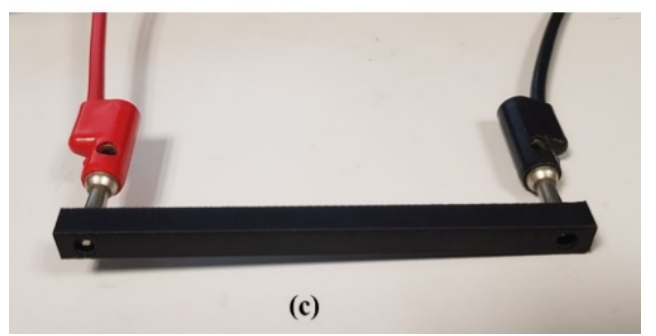

Fig. 8. The resistance measurements specimens: a) the $\mathrm{Z}$ direction $\mathrm{CAD}$ model; $\mathrm{b}$ ) the $\mathrm{Y}$ direction $\mathrm{CAD}$ model; c) the $\mathrm{Y}$ direction 3D printed specimen 


\section{EXPERIMENTAL METHODS}

\subsection{Application A: Water Temperature Indicator}

Generally commercial temperature indicators show when the temperature of the shower or wash hand basin is above a safe level to reduce the risk of scalding. They are preset within a safe range which is typically 35 to $40{ }^{\circ} \mathrm{C}$ for the shower, and to about $45^{\circ} \mathrm{C}$ for the wash basin. The currently developed temperature indicator is based on a thermally-induced colour change from blue at $\sim 20^{\circ} \mathrm{C}$ gradually into white. Three components, a colour former, a developer, and a co-solvent, are needed to produce a gauge with reversible colour change, and the change is driven by their interactions. The sensor consists of a mixture of three-component organic materials, consisting of a Leuco dye as the colour former, a weak acid acting as colour developer, and a low temperature melting co-solvent. The solvent breaks down the dye-developer bond resulting in colour change when exposed to high temperatures (above its melting point). The coloured complex of a colour former and a developer prevails below the melting point of the co-solvent. When the co-solvent melts, the dye developer complex is destroyed, and the three-component system becomes colourless. Typically, the melting point of the applied co-solvent determines the temperature at which the colour change occurs.
The 4D-printed water temperature indicator was successfully printed, and the device was effectively inserted on the shower tap (Fig. 9a). It has been shown that the thermo-responsive indicator turned from blue at cold temperatures $\left(\sim 20^{\circ} \mathrm{C}\right)$ gradually into white upon exposure to a warmer temperature of up to $\sim 40^{\circ} \mathrm{C}$ (Fig. 9b-c and Fig. 10).

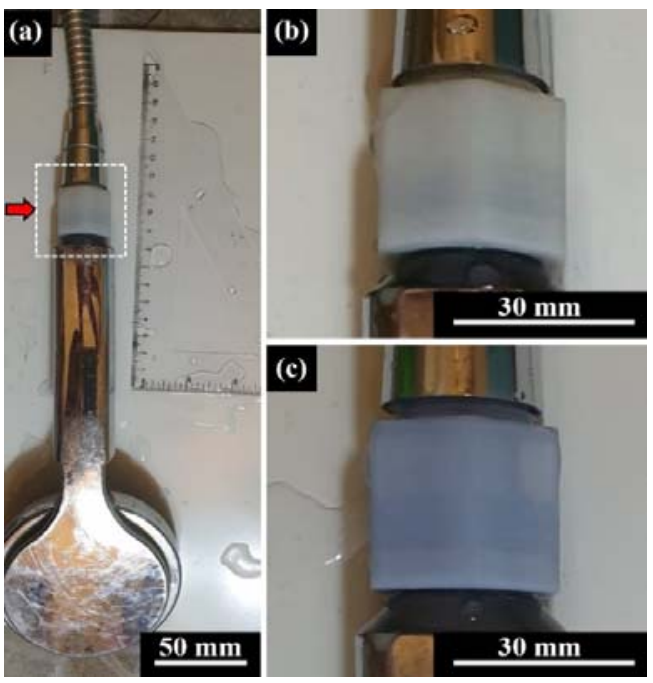

Fig. 9. The AM-FFF thermo-responsive water temperature indicator device joint to the shower tap: a) general view; b) at working temperature of $\sim 40^{\circ} \mathrm{C}$; c) at working temperature of $\sim 20^{\circ} \mathrm{C}$

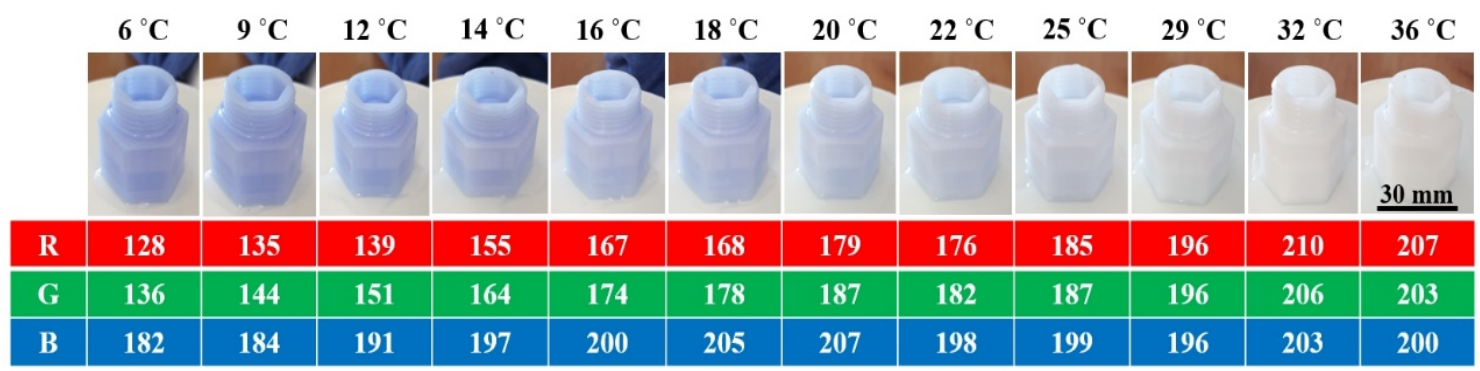

Fig. 10. The AM-FFF thermo-responsive water temperature indicator temperature and colourscale

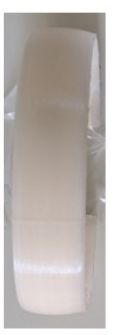

$96 \mathbf{l x}$

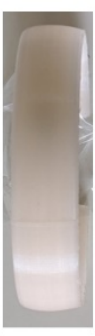

$145 \mathrm{~lx}$

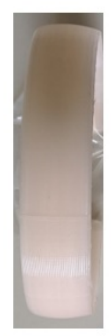

$2051 x$

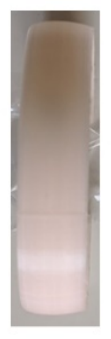

$288 \mathbf{l x}$

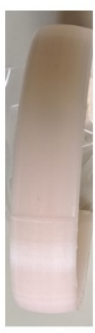

501 lx

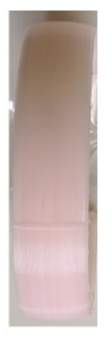

802 lx

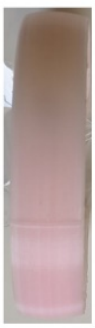

$1440 \mathrm{~lx}$
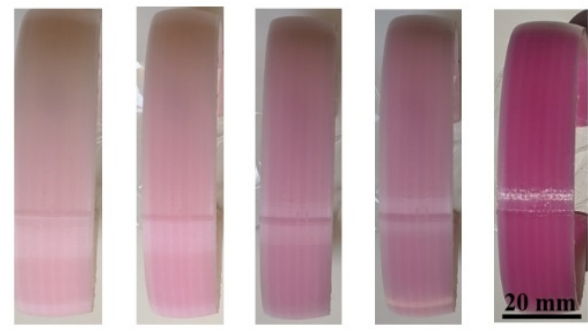

2265 lx

3763 lx 5784 lx 6089 lx

$67823 \mathrm{~lx}$

Fig. 11. The AM-FFF sunlight/UV indicator bracelet made of photo-responsive polymer: UV radiation and colourscale (the white colour is low in sunlight and the red (fuchsia pink) colour is intense in sunlight 


\subsection{Application B: Sunlight / UV Indicator Bracelet}

Humans in general, and people with albinism, can enjoy the outdoors by limiting their exposure to sunlight, wearing the right clothing, and using suitable sunscreens cautiously.

The invisible part of the sunlight spectrum, both short and long wavelength ultraviolet light, damages the skin. Therefore, we provided a bracelet printed by photopolymers which are sensitive to the intensity of sunlight/UV and alert to the intensity of exposure by changing colour.

The 4D-printed sunlight / UV indicator bracelet was successfully printed and the part changed its colour from white, meaning pre-exposure to sunlight, gradually into red when exposed to intense sunlight (Fig. 11). Photo-induced colour change was measured after exposing the object to the sun on a bright day (between 12:00 and 13:00), for different intervals. As expected, the colour change values of the RED photoresponsive polymer were directly affected by the exposure time and intensity of sunlight.

Low light emission was obtained from the white bracelet (91 lx) while, as the light emission increased, the bracelet changed to a redder color. The maximum exposure was at $67823 \mathrm{~lx}$, at which the bracelet turned into a fuchsia pink colour as seen in figure 11.

\subsection{Application C: Professional Smart Business Card Stand for Office Tabletop}

The parts of the 4D-printed professional smart business card stand were successfully printed (Fig. 7). The conductive polymer caused the UV LEDs to light up when electrical voltage was supplied, and the UV light caused the colour of the letters to change from white to red (Fig. 12).

The electrical resistance of the five 3D-printed electrical conductive PLA polymer samples was measured by means of four-point and two-point methods. The contact resistance was small $( \pm 2 \%)$ relative to the total resistance, hence the two point method was adapted for all resistance measurements.
The measured resistance values were between $300.1 \Omega$ and $320.1 \Omega$, with an average resistance of $306.4 \pm 8.5 \Omega$ for the $Z$ direction, and between $342.9 \Omega$ and $378.0 \Omega$, with an average resistance of $362.5 \pm 15.5 \Omega$ for the $Y$ direction (Table 2).

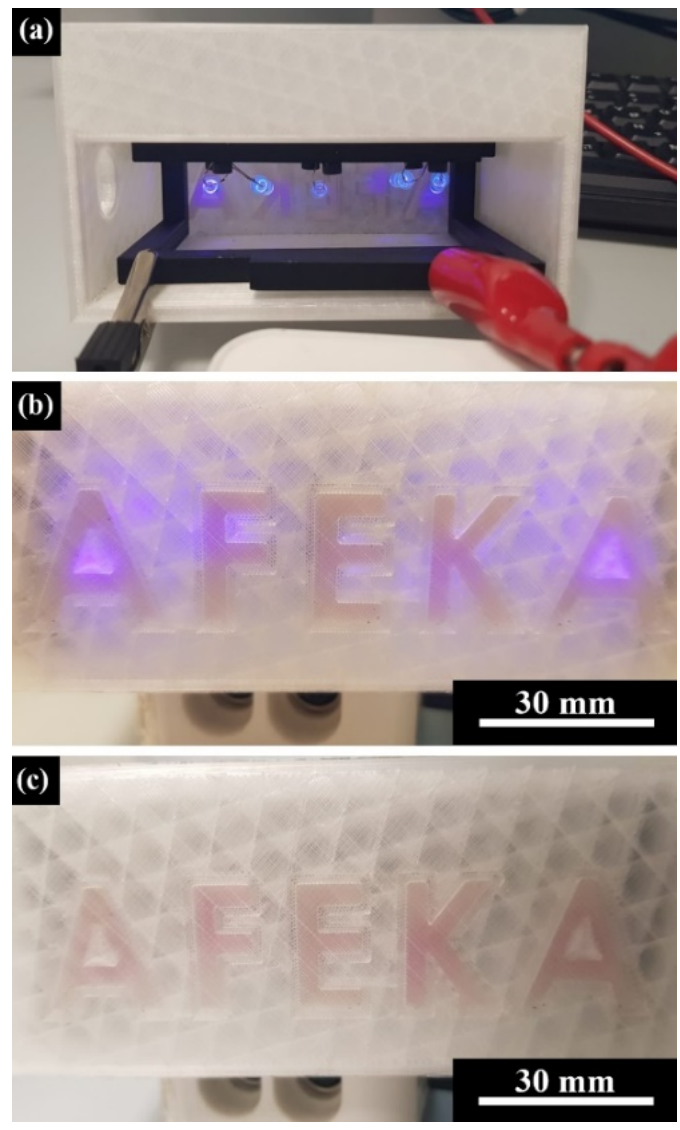

Fig. 12. The 4D-printed AM-FFF card holder during demonstration:

a) generation of UV light; b) the AFEKA logo, made of photo-responsive PLA changes colourfrom white to red because of the UV light; c) the card holder after removal of the UV light source

Table 2. Resistance measurements of the electrical conductive PLA polymer bars 3D printed samples.

(This polymer was used in order to print the conductive part of the professional smart business card-stand)

\begin{tabular}{|c|c|c|c|c|c|c|c|c|}
\hline \multirow{2}{*}{$\begin{array}{l}\text { Specimen no./ } \\
\text { direction }\end{array}$} & \multicolumn{5}{|c|}{ Resistance ( $\Omega$ ) } & \multirow{2}{*}{$\begin{array}{c}\text { Average } \\
\text { resistance } \\
{[\Omega]}\end{array}$} & \multirow{2}{*}{$\begin{array}{l}\text { Standard } \\
\text { deviation } \\
\text { (S.D.) }\end{array}$} & \multirow{2}{*}{$\begin{array}{c}\text { Average specific } \\
\text { electrical resistance } \\
{[\Omega \cdot \mathbf{m}]}\end{array}$} \\
\hline & 1 & 2 & 3 & 4 & 5 & & & \\
\hline $\mathrm{Z}$ direction & 301.2 & 301.1 & 320.1 & 300.2 & 309.5 & 306.4 & 8.5 & 0.167 \\
\hline Y direction & 342.9 & 378.0 & 355.3 & 378.6 & 357.5 & 362.5 & 15.5 & 0.197 \\
\hline
\end{tabular}

\section{SUMMARY}

Three applications were designed and manufactured by the FFF AM technology in order to demonstrate the feasibility of 4D printing technology of SRP: (1) a water temperature indicator for a shower tap, (2) a sunlight/UV indicator bracelet, and (3) a smart business card stand for an office tabletop. The 
analysis of the water temperature indicator's performance was based on examining the colour changes of a thermo-responsive CCT BLUE polymer depending on temperature.

The analysis of the sunlight/UV indicator's capability was based on examining the colour changes depending on exposure to sunlight/UV radiation. The electrical conductivity of the conductive PLA polymer was tested by performing resistance measurements. All three objects were successfully 3D-printed and their functionality was demonstrated.The ability to acquire unique colours at different temperatures and by temperature changes numerous times, or the ability to change colour by being exposed to sunlight/UV radiation makes smart polymers particularly attractive for many applications. For example, thermochromic materials could be used as time-temperature indicators for smart packaging, able to communicate visual indications of whether goods (food, pharmaceuticals, inks etc.) have experienced unwanted time-temperature incidents.

These examples are sure to help increase the interest in FFF 4D printed stimuli-responsive polymer applications. Much R\&D remains to be done in designing the objects and developing the FFF printing parameters, so as to take advantage of stimuliresponsive polymers being developed for this technology.

\section{ACKNOWLEDGEMENTS}

The research was supported by the Afeka Academic College of Engineering, to whom the authors are grateful. Thanks are also due to T. Katsir and R. Gabay from SYNERGY R.M ltd., Israel. Thanks also go to V. Palei, S. Maman and N. Elenberg, from the Afeka Academic College of Engineering, for their great engineering assistance and technical support. The authors would like to thank B. Doron for the English editing.

\section{REFERENCES}

[1] Tibbits S., $4 D$ printing: multi-material shape change, Architectural Design 84(1), 2014, pp. 116-121.

[2] Ge Q., Sakhaei A. H., Lee H., Dunn C. K., Fang N. X., Dunn M. L., Multimaterial $4 D$ printing with tailorable shape memory polymers, Scientific Reports 6, 2016, p. 31110.

[3] Mitchell A., Lafont U., Hołyńska M., Semprimoschnig C., Additive manufacturing - A review of $4 D$ printing and future applications, Additive Manufacturing 24, 2018, pp. 606-626.

[4] Sossou G., Demoly F., Montavon G., Gomes S., Design for $4 D$ printing: rapidly exploring the design space around smart materials, Procedia CIRP 70, 2018, pp. 120-125.

[5] Shafranek R. T., Millik S. C., Smith P. T., Lee C. U., Boydston A. J., Nelson A., Stimuli-responsive materials in additive manufacturing, Progress in Polymer Science 94, 2019, pp. 36-67.

[6] Rastogi P., Kandasubramanian B., Breakthrough in the printing tactics for stimuli-responsive materials: $4 D$ printing, Chemical Engineering Journal 366, 2019, pp. 264-304.

[7] Kuang X., Roach D. J., Wu J., Hamel C. M., Ding Z., Wang

T., Dunn M. L., Qi H. J., Advances in 4D printing: Materials and applications, Advanced Functional Materials 29(2), 2019, p. 1805290 .
[8] Baker A. B., Bates S. R., Llewellyn-Jones T. M., Valori L. P., Dicker M. P., Trask R. S., $4 D$ printing with robust thermoplastic polyurethane hydrogel-elastomer trilayers, Materials \& Design 163,2019 , p. 107544

[9] Zhang Z., Demir K. G., Gu G. X., Developments in 4Dprinting: a review on current smart materials, technologies, and applications, International Journal of Smart and Nano Materials $10(3), 2019$, pp. 205-224.

[10] González-Henríquez C. M., Sarabia-Vallejos M. A., Rodriguez-Hernandez J., Polymers for additive manufacturing and 4D-printing: Materials, methodologies, and biomedical applications, Progress in Polymer Science 94, 2019, pp. 57-116.

[11] Ma S., Zhang Y., Wang M., Liang Y., Ren L., Ren L., Recent progress in $4 D$ printing of stimuli-responsive polymeric materials, Science China Technological Sciences 63(4), 2020, pp. 544-532.

[12] Deshmukh K., Muzaffar A., Kováŕík T., Křenek T., Ahamed M. B., Pasha S. K., Fundamentals and applications of 3D and 4D printing of polymers: Challenges in polymer processing and prospects of future research (Chapter 17), In: Sadasivuni, K.K, Deshmukh, K., Almaadeed, M.A. (Eds.), 3D and 4D Printing of Polymer Nanocomposite Materials. Processes, Applications, and Challenges 2020, Elsevier, Amsterdam, pp. 527-560.

[13] Wu H., Zhang X., Ma Z., Zhang C., Ai J., Chen P., Yan C., Su B., Shi Y., A Material combination concept to realize $4 D$ printed products with newly emerging property/functionality, Advanced Science 7(9), 2020, p. 1903208.

[14] Sabahi N., Chen W., Wang, C. H., Kruzic J. J., Li X., $A$ review on additive manufacturing of shape-memory materials for biomedical applications, JOM 72(3), 2020, pp. 1229-1253.

[15] Geng P., Zhao J., Wu W., Ye W., Wang Y., Wang S., Zhang S., Effects of extrusion speed and printing speed on the $3 D$ printing stability of extruded PEEK filament, Journal of Manufacturing Processes 37, 2019, pp. 266-273.

[16] Seeboth A., Lötzsch D., Ruhmann R., First example of a non-toxic thermochromic polymer material-based on a novel mechanism, Journal of Materials Chemistry C 1(16), 2013, pp. 2811-2816.

[17] Wang Y., Runnerstrom E. L., Milliron D. J., Switchable materials for smart windows, Annual Review of Chemical and Biomolecular Engineering 7, 2016, pp. 283-304.

[18] Kulčar R., Friškovec M., Hauptman N., Vesel A., Gunde

M. K., Colorimetric properties of reversible thermochromic printing inks, Dyes and pigments 86(3), 2010, pp. 271-277.

[19] Aklujkar P. S., Kandasubramanian B. A review of microencapsulated thermochromic coatings for sustainable building applications, Journal of Coatings Technology and Research, 2020. https://doi.org/10.1007/s11998-020-00396-3

[20] Zhu X., Liu Y., Dong N., Li Z., Fabrication and characterization of reversible thermochromic wood veneers, Scientific Reports 7(1), 2017, pp. 1-10.

[21] Mehta S., Kushwaha A., Kisannagar, R. R., Gupta D. Fabrication of a reversible thermochromism based temperature sensor using an organic-inorganic composite system, RSC Advances 10(36), 2020, pp. 21270-21276.

[22] Seeboth A., Ruhmann R. Mühling, O., Thermotropic and thermochromic polymer-based materials for adaptive solar control, Materials 3(12), 2010, pp. 5143-5168.

[23] Bašnec K., Perše L.S., Šumiga B., Huskić M., Meden A., Hladnik A., Podgornik B. B., Gunde M. K., Relation between colour-and phase changes of a leuco dye-based thermochromic composite, Scientific Reports 8(1), 2018, pp. 1-10.

[24] Seeboth A., Ruhmann R., Mühling O., Thermotropic and thermochromic polymer based materials for adaptive solar control, Materials 3(12), 2010, pp.5143-5168.

[25] Manouras T., Vamvakaki M., Field responsive materials: photo-, electro-, magnetic-and ultrasound-sensitive polymers, Polymer Chemistry 8(1), 2017, pp. 74-96.

[26] Jerca F. A., Jerca V. V., Hoogenboom R., Photoresponsive polymers on the move, Chem 3(4), 2017, pp. 533-536.

[27] Pandey R., Photopolymers in $3 D$ printing applications, Degree Thesis Plastics Technology, Arcada University of Applied Sciences, Helsinki, 2014.

[28] Abdollahi A., Roghani-Mamaqani H., Razavi B., SalamiKalajahi M., The light-controlling of temperature-responsivity in stimuli-responsive polymers. Polymer Chemistry 10(42), 2019, pp. 
5686-5720.

[29] Kennedy Z. C., Stephenson D. E., Christ J. F., Pope T. R., Arey B. W., Barrett C. A., Warner M. G., Enhanced anticounterfeiting measures for additive manufacturing: coupling lanthanide nanomaterial chemical signatures with blockchain technology. Journal of Materials Chemistry C 5(37), 2017, pp. 9570-9578

[30] Daniel F., Patoary N. H., Moore A. L., Weiss L., Radadia A. D., Temperature-dependent electrical resistance of conductive polylactic acid filament for fused deposition modeling, The International Journal of Advanced Manufacturing Technology 99(5-8), 2018, pp. 1215-1224.
[31] Flowers P. F., Reyes C., Ye S., Kim M. J., Wiley B. J., $3 D$ printing electronic components and circuits with conductive thermoplastic filament, Additive Manufacturing 18, 2017, pp. 156163.

[32] Kwok S. W., Goh K. H. H., Tan Z. D., Tan S. T.M., Tjiu W. W., Soh J. Y., Ng Z. J. G., Chan Y. Z., Hui H. K., Goh K. E. J., Electrically conductive filament for 3D-printed circuits and sensors, Applied Materials Today, 9, 2017, pp. 167-175.

[33] Rafiee M., Farahani R. D., Therriault D., Multi-material 3D and $4 D$ printing: A survey, Advanced Science 2020, p.1902307. DOI: $10.1002 /$ advs.20190230 